Key Words:

Oxalic acid,

Tank Closure,

Chemical

cleaning

Retention:

Permanent

\title{
Oxalate Mass Balance during Chemical Cleaning in Tank 5F
}

\author{
Michael R. Poirier \\ Samuel D. Fink
}

July 8, 2011

Savannah River National Laboratory

Savannah River Nuclear Solutions

Aiken, SC 29808 


\section{DISCLAIMER}

This work was prepared under an agreement with and funded by the U.S. Government. Neither the U. S. Government or its employees, nor any of its contractors, subcontractors or their employees, makes any express or implied:

1. warranty or assumes any legal liability for the accuracy, completeness, or for the use or results of such use of any information, product, or process disclosed; or

2. representation that such use or results of such use would not infringe privately owned rights; or

3. endorsement or recommendation of any specifically identified commercial product, process, or service.

Any views and opinions of authors expressed in this work do not necessarily state or reflect those of the United States Government, or its contractors, or subcontractors.

Printed in the United States of America

Prepared for

U.S. Department of Energy 
Key Words:

MCU,

Solvent

Extraction,

Coalescer

Retention:

Permanent

\title{
Oxalate Mass Balance during Chemical Cleaning in Tank $5 F$
}

\author{
Michael R. Poirier \\ Samuel D. Fink
}

July 8, 2011

Savannah River National Laboratory

Savannah River Nuclear Solutions

Savannah River Site

Aiken, SC 29808 


\section{REVIEWS AND APPROVALS}

\section{Authors}

M. R. Poirier, SRNL, Advanced Characterization \& Processing

Date

S. D. Fink, SRNL, Separations and Actinide Science Programs

Date

\section{Design Check}

M. S. Hay, SRNL, Advanced Characterization \& Processing

Date

\section{Management}

F. M. Pennebaker,, Manager, SRNL, Advanced Characterization \& Processing Date

S. L. Marra, Manager, SRNL E\&CPT Research Programs

Date

\section{Customer}

W. L. Isom, Jr., Manager, Closure Projects Engineering

Date 


\section{TABLE OF CONTENTS}

LIST OF TABLES ...................................................................................................................iii

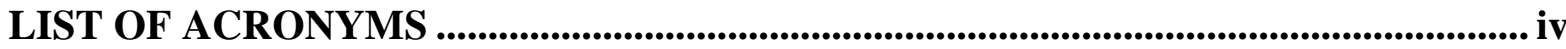

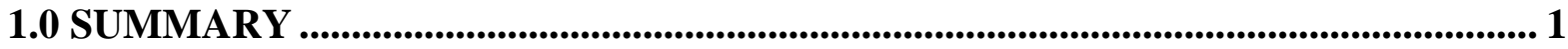

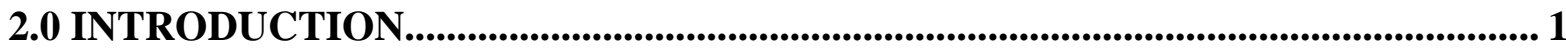

3.0 EXPERIMENTAL WORK....................................................................................... 3

3.1 Reagent Preparation.......................................................................................... 3

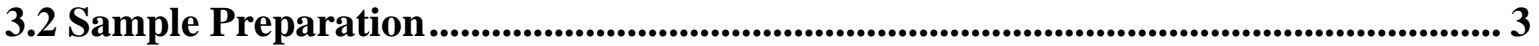

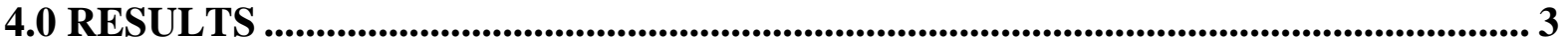

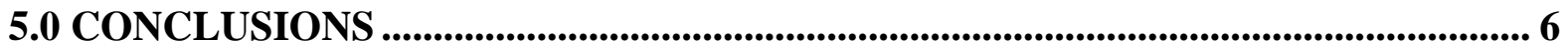

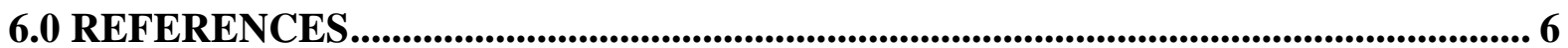

\section{LIST OF TABLES}

Table 1. Anion Analysis of Tank 5F Liquid Samples ..................................................... 3

Table 2. Oxalate Leached from Tank 5F Process Sample ................................................... 4 


\section{LIST OF ACRONYMS}

$\begin{array}{ll}\text { AD } & \text { Analytical Development } \\ \text { IC } & \text { Ion Chromatography } \\ \text { ICPES } & \text { Inductively Coupled Plasma Emission Spectroscopy } \\ \text { LWO } & \text { Liquid Waste Organization } \\ \text { SMP } & \text { Submersible Mixer Pumps } \\ \text { SRNL } & \text { Savannah River National Laboratory } \\ \text { SRS } & \text { Savannah River Site }\end{array}$




\subsection{SUMMARY}

The Savannah River Site (SRS) is preparing Tank 5F for closure. The first step in preparing the tank for closure is mechanical sludge removal. Following mechanical sludge removal, SRS performed chemical cleaning with oxalic acid to remove the sludge heel. Personnel are currently assessing the effectiveness of the chemical cleaning to determine whether the tank is ready for closure.

SRS personnel collected liquid samples during chemical cleaning and submitted them to Savannah River National Laboratory (SRNL) for analysis. Following chemical cleaning, they collected a solid sample (also known as "process sample") and submitted it to SRNL for analysis. The authors analyzed these samples to assess the effectiveness of the chemical cleaning process. Analysis of the anions showed the measured oxalate removed from Tank 5F to be approximately $50 \%$ of the amount added in the oxalic acid. To close the oxalate mass balance, the author collected solid samples, leached them with nitric acid, and measured the concentration of cations and anions in the leachate.

The conclusions from this work follow.

- Approximately $50 \%$ of the oxalate added as oxalic acid was removed with the decanted liquid.

- Approximately 2-6\% of the oxalate (added to the tank as oxalic acid) formed precipitates with compounds such as nickel, manganese, sodium, and iron (II), and was dissolved with nitric acid.

- As much as 30\% of the oxalate may have decomposed forming carbon dioxide.

The balance of the oxalate is not accounted for in the analyses and represents the overall uncertainties in the analyses and sampling.

\subsection{INTRODUCTION}

Savannah River Remediation (SRR) is preparing Tank 5F for closure. The first step in preparing the tank for closure is mechanical sludge removal. In mechanical sludge removal, personnel add liquid (e.g., inhibited water or supernate salt solution) to the tank to form a slurry. They mix the liquid and sludge with pumps, and transfer the slurry to another tank for further processing. Mechanical sludge removal effectively removes the bulk of the sludge from a tank, but is not able to remove all of the sludge. In Tank 5F, a sludge heel with estimated volume of 3,453 gallons remained after mechanical sludge removal. (The volumes of sludge in Tank $5 \mathrm{~F}$ and the volumes of acid and water added are from a Liquid Waste Organization (LWO) document. The volumes reported in this document use the same number of significant figures as the LWO document). ${ }^{\text {i }}$

SRR developed a Chemical Cleaning process to remove these sludge heels using oxalic acid. They developed a flowsheet based on SRNL testing and LWO modeling. . $^{\text {ii,iii,iv }}$ The flowsheet washes the sludge with well water prior to chemical cleaning to reduce the ionic strength and increase the oxalate solubility. The flowsheet employs one strike with $8 \mathrm{wt} \%$ oxalic acid at an acid:sludge ratio of 20:1, followed by two strikes with 8 wt \% oxalic acid at an acid:sludge ratio 
of 13:1. The tank is mixed to promote sludge dissolution and the liquid pumped to Tank 7F. Following the acid strikes, a Water Wash is performed to remove residual acid from the tank walls and cooling coils. Following each acid/water addition, SRR collects liquid samples and

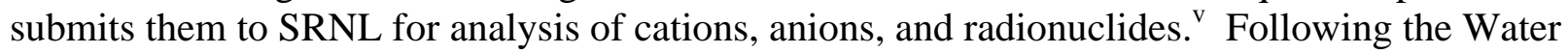
Wash, SRR collects solid samples and submits them to SRNL for analysis of cations and radionuclides. ${ }^{\text {vi }}$

The Tank 5F chemical cleaning included two oxalic acid strikes, a Spray Wash (with oxalic acid and water), and a Water Wash. The cleaning protocols did not wash the sludge prior to Oxalic Acid Strike 1.

The first oxalic acid strike used the following protocol. Personnel added 67,468 gallons of 8 wt \% oxalic acid to Tank 5F. Following the oxalic acid addition, they added 43,177 gallons of well water and mixed the contents of Tank 5F with two submersible mixer pumps (SMPs) for approximately four days. Following the mixing, SRR transferred 111,381 gallons of Tank 5F material to Tank 7F. The SMPs were operating at the start of the transfer and turned off when the liquid level dropped. The transfer lasted approximately 13 hours, with the SMPs operating for the first 6 hours. ${ }^{i}$ Personnel collected a sample of the liquid from Tank 5F and submitted it to SRNL for analysis. ${ }^{\text {vii }}$ Mapping of the tank following the transfer indicated that 2,745 gallons of solids remained in the tank.

The second oxalic acid strike proceeded as follows. SRR added 32,743 gallons of 8 wt \% oxalic acid to Tank 5F. Following the acid addition, personnel visually inspected the tank and transferred 30,891 gallons of Tank 5F material to Tank 7F. viii A sample of the liquid from Tank 5F was collected and submitted to SRNL for analysis. ${ }^{\text {vii }}$ Mapping of the tank following the transfer indicated that 3,592 gallons of solids remained in the tank. ${ }^{\text {viii }}$

Following the oxalic acid strikes, SRR performed Spray Washing to remove waste collected on internal structures, cooling coils, tank top internals, and tank walls. The Acid Spray Wash was followed by a Water Spray Wash to remove oxalic acid from the tank internals. SRR conducted the Spray Wash as follows. Personnel added 4,821 gallons of $8 \mathrm{wt} \%$ oxalic acid to Tank 5F through the spray mast installed in Riser 7 and 4,824 gallons of oxalic acid through Riser 2 . They added 5,000 gallons of deionized water into the tank via Riser 2 and 5,000 gallons of deionized water into the tank via Riser 7. Following the Spray Wash, personnel visually inspected the tank and transferred 26,224 gallons of Tank 5F material to Tank 7F. ${ }^{\text {ix }}$ They collected a sample of the liquid from Tank 5F and submitted it to SRNL for analysis. ${ }^{\text {vii }}$

Following the Spray Wash and transfer, SRR added 99,230 gallons of well water to Tank 5F, mixed the tank contents with a single SMP, and transferred the liquid from Tank 5F to Tank 7F. ${ }^{\text {ix }}$ Personnel collected a sample of the liquid from Tank 5F and submitted it to SRNL for analysis. ${ }^{\text {vii }}$ Mapping of the tank following the transfer indicated that 3,300 gallons of solids remained in the tank.

Following the Water Wash, SRR personnel collected a solid sample (i.e., process sample) and submitted it to SRNL for analysis to assess the effectiveness of the chemical cleaning and to provide a preliminary indication of the composition of the material remaining in the tank. 
The analysis of the liquid samples showed the measured oxalate to be much less than the amount of oxalic acid added to the tank (see Table 1). ${ }^{\text {vii }}$

Table 1. Anion Analysis of Tank 5F Liquid Samples

$\underline{\text { Species }}$

Oxalate

Expected

oxalate

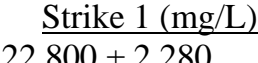

Strike $2(\mathrm{mg} / \mathrm{L})$

$49,100 \pm 4,910$

79,200 $\frac{\text { Spray Wash }(\mathrm{mg} / \mathrm{L})}{24,000 \pm 2,400}$

49,300

\author{
$\frac{\text { Water Wash (mg/L) }}{1,000+100}$
}

1,900

\subsection{EXPERIMENTAL WORK}

SRNL received a solid sample from Tank 5F (FTF-05-09-49). Personnel performed a nitric acid leach of the sample to attempt to quantify the amount of oxalate present. They performed the leach as follows.

\subsection{REAGENT PREPARATION}

Personnel prepared $~ 200 \mathrm{~mL}$ of $0.25 \mathrm{M}$ nitric acid. We selected the nitric acid concentration based on SRNL's Alternative Enhanced Chemical Cleaning Studies. ${ }^{\mathrm{x}}$

\subsection{SAMPLE PREPARATION}

They placed $\sim 0.2 \mathrm{~g}$ of Tank 5F sludge (FTF-05-09-49) into each of two poly bottles. They added $\sim 20$ grams of nitric acid to each bottle, gently mixed the bottles, allowed the bottles to sit for one hour, collected two samples from each bottle, filtered the samples with a $0.45 \mu$ syringe filter, and submitted the samples to Analytical Development (AD) for analysis by Inductively Coupled Plasma - Emission Spectroscopy (ICP-ES) and Ion Chromatography (IC). These samples are referred to as Sample 1 and 2.

Following analysis of these samples, we performed a second leach on the remaining solids (Referred to as Samples 11 and 12). For this leachate, we decanted the supernate from the bottles, added $\sim 40$ grams of nitric acid to each bottle, gently mixed the bottles, allowed the bottles to sit for one hour, collected two samples from each bottle, filtered the samples with a $0.45 \mu$ syringe filter, and submitted the samples to AD for analysis by ICP-ES and IC.

\subsection{RESULTS}

Table 2 shows the results from the analysis of the acid leach solutions. The concentrations listed in the table are the average of two replicates. The results show a large amount of oxalate in the first leach samples (Samples 1 and 2). In addition, these samples show large amounts of nickel, manganese, sodium, and iron. Nickel is known to form a precipitate with oxalate. ${ }^{\mathrm{xi}}$ Previous XRD analyses of these solids showed the presence of nickel oxalate. ${ }^{x i i}$ Manganese and iron (II) and iron (III) also will form precipitates with oxalate. ${ }^{\text {xii }}$ The sodium concentration in the first leach is of the same magnitude, but lower, than the iron, manganese, and nickel concentrations. The sodium is likely from the dissolution of sodium oxalate or sodium bioxalate. If the nickel and manganese are present as oxalate compounds, the solid samples should contain one mole of 
oxalate for each mole of nickel or manganese. If the sodium is present as sodium oxalate, the solid samples will contain two moles of sodium per mole of oxalate. If the sodium is present as sodium bioxalate, the solid samples will contain one mole of sodium per mole of oxalate. The iron could be present as an iron oxalate or as an iron oxide, such as hematite, maghemite, or goethite. The XRD analysis showed the primary crystalline iron compounds to be hematite and magnetite. ${ }^{\text {xii }}$ Therefore, the moles of oxalate should be greater than the moles of nickel plus manganese plus sodium, and less than the moles of nickel plus manganese plus sodium plus iron. Considering the uncertainty in the data, there is good agreement between the molar concentrations of manganese, nickel, and oxalate.

Table 2. Oxalate Leached from Tank 5F Process Sample

\begin{tabular}{|c|c|c|c|c|}
\hline Process Sample & $\underline{\text { Sample } 1}$ & Sample 2 & Sample 11 & Sample 12 \\
\hline & & & & \\
\hline $\mathrm{Fe}$ & 26.7 & 8.7 & 11.1 & 4.6 \\
\hline $\mathrm{Mn}$ & 21.7 & 8.3 & 5.8 & 3.3 \\
\hline $\mathrm{Ni}$ & 17.7 & 6.2 & 8.8 & 5.2 \\
\hline $\mathrm{Na}$ & 4.8 & 2.0 & 0.5 & 0.3 \\
\hline Oxalate & 73.7 & 23.9 & $<7.6$ & $<7.6$ \\
\hline \multicolumn{5}{|c|}{ Concentration (Mole/kg) } \\
\hline $\mathrm{Fe}$ & 0.48 & 0.16 & 0.20 & 0.08 \\
\hline Mn & 0.40 & 0.15 & 0.11 & 0.06 \\
\hline $\mathrm{Ni}$ & 0.30 & 0.11 & 0.15 & 0.09 \\
\hline $\mathrm{Na}$ & 0.21 & 0.09 & 0.02 & 0.01 \\
\hline $\mathrm{Fe}+\mathrm{Mn}+\mathrm{Ni}+\mathrm{Na}$ & 1.39 & 0.50 & 0.48 & 0.24 \\
\hline Oxalate & 0.84 & 0.27 & $<0.09$ & $<0.09$ \\
\hline \multicolumn{5}{|c|}{ Amount Leached (Mole) } \\
\hline $\mathrm{Fe}$ & 11,932 & 3,889 & 4952 & 2064 \\
\hline Mn & 9,881 & 3,770 & 2639 & 1489 \\
\hline $\mathrm{Ni}$ & 7,551 & 2,657 & 3743 & 2228 \\
\hline $\mathrm{Na}$ & 5,266 & 2,165 & 547 & 301 \\
\hline Oxalate & 20,914 & 6,798 & $<2,160$ & $<2,170$ \\
\hline \multicolumn{5}{|c|}{ Fraction of Species in Solids Following Chemical Cleaning Dissolved } \\
\hline $\mathrm{Fe}$ & $14 \%$ & $5 \%$ & $6 \%$ & $2 \%$ \\
\hline Mn & $62 \%$ & $24 \%$ & $17 \%$ & $9 \%$ \\
\hline $\mathrm{Ni}$ & $21 \%$ & $7 \%$ & $10 \%$ & $6 \%$ \\
\hline Oxalate & $13 \%$ & $4 \%$ & $<1 \%$ & $<1 \%$ \\
\hline
\end{tabular}

The analysis of Samples 11 and 12 shows a significant reduction in the amount of oxalate, nickel, manganese, sodium, and iron dissolved. The result suggests that little oxalate would be recovered by an additional nitric acid leach, and most of the insoluble oxalate has been recovered by the first leach. The results show the addition of dilute nitric acid was effective in dissolving additional iron, manganese, and nickel, and might be effective in dissolving species that have low solubility in oxalic acid, such as plutonium. 
Table 2 shows that a small fraction of the oxalate was dissolved by the nitric acid, and minimal oxalate dissolved in the second leach. The second leach dissolved additional iron, manganese, and nickel. To determine the fate of the oxalate, we performed an oxalate balance.

In Test $1\left(50{ }^{\circ} \mathrm{C}\right.$, Mixing) of the Tank 5F Oxalic Acid Cleaning Simulant Test, $55 \mathrm{~L}$ of gas was generated (assumed to be $\mathrm{CO}_{2}$ ). ${ }^{\text {iii }}$ This volume of gas is equivalent to 2.08 moles $\mathrm{CO}_{2}$. Since

$$
\begin{aligned}
& \mathrm{Fe}^{+3}+3 \mathrm{C}_{2} \mathrm{O}_{4}{ }^{-2} \rightarrow \mathrm{Fe}\left(\mathrm{C}_{2} \mathrm{O}_{4}\right)_{3}{ }^{-3} \\
& \mathrm{Fe}\left(\mathrm{C}_{2} \mathrm{O}_{4}\right)_{3}{ }^{-3}+\text { light } \rightarrow \mathrm{Fe}\left(\mathrm{C}_{2} \mathrm{O}_{4}\right)+\mathrm{C}_{2} \mathrm{O}_{4}{ }^{-2}+2 \mathrm{CO}_{2}
\end{aligned}
$$

2.08 moles of $\mathrm{CO}_{2}$ could be produced from 1.04 moles of oxalate. The test solution contained $7656 \mathrm{~mL}$ of $8 \mathrm{wt} \%(0.92 \mathrm{M})$ oxalic acid, which is equivalent to $(7.656 \mathrm{~L})(0.92 \mathrm{~mole} / \mathrm{L})=7.04$ moles oxalate. Dividing 1.04/7.04 $=0.15$ yields the amount of $\mathrm{CO}_{2}$ gas generated is $15 \%$ of potential theoretical yield from oxalic acid decomposition. According to the mechanism described above, the maximum amount of oxalate that could decompose to form carbon dioxide is 33\%. Another mechanism for carbon dioxide generation is the acidification of carbonate. The feed in Test 1 contained 0.32 moles of carbonate. The maximum amount of carbon dioxide the carbonate could form is 0.32 moles, approximately $15 \%$ of the carbon dioxide formed.

In Actual Waste Test $1\left(50{ }^{\circ} \mathrm{C}\right.$, Mixing), the calculated volume of gas generated from adding 100,000 gallons of $8 \mathrm{wt} \%$ oxalic acid is $184,000 \mathrm{ft}^{3}$. ${ }^{\text {ii }}$ Since SRR added 67,468+32,743+9645 = 109,856 gallons of $8 \mathrm{wt} \%$ oxalic acid to Tank 5F, they could have produced $\left(184,000 \mathrm{ft}^{3}\right)(1.10)\left(28.317 \mathrm{~L} / \mathrm{ft}^{3}\right)=5.7 \times 10^{6} \mathrm{~L}^{3}$ of $\mathrm{CO}_{2}$. This volume is equivalent to $1.08 \times 10^{5}$ moles of $\mathrm{CO}_{2}$. The amount of oxalate added to Tank $5 \mathrm{~F}$ (in the oxalic acid) is $3.04 \times 10^{7}$ grams or $3.46 \times 10^{5}$ moles of oxalate. The fraction of oxalate that could have decomposed to $\mathrm{CO}_{2}$ is $1.08 / 3.46=0.31$, which is close to the theoretical maximum of 33\%. According to Actual Waste Test data, 31\% of oxalate added would decompose to form $\mathrm{CO}_{2}$. The amount of carbonate in the feed for this test is not known.

In the simulant and actual waste tests, the feed slurry was exposed to light which is needed for the decomposition reaction. While the interior of Tank $5 \mathrm{H}$ is dark, it is exposed to high doses of radiation, which may help the oxalate decomposition reaction.

The mass balance for Tank $5 \mathrm{~F}$ is shown below

$3.83 \times 10^{5}$ moles of oxalate added to the tank based on the volumes and concentration of oxalic acid added to the tank.

$1.20 \times 10^{5}$ moles of oxalate could have decomposed to form $\mathrm{CO}_{2}$ based on the $\mathrm{CO}_{2}$ generation measured in the Actual Waste Test conducted at $50{ }^{\circ} \mathrm{C}$.

$2.63 \times 10^{5}$ moles of oxalate remaining after subtracting the oxalate that could have decomposed from the oxalate added to the tank.

$2.07 \times 10^{5}$ moles of oxalate removed in liquid based on analysis of the liquid samples.

$0.56 \times 10^{5}$ moles of oxalate remaining in the tank following chemical cleaning. This amount is $\sim 15 \%$ of the amount of oxalate added to the tank. Of the oxalate calculated to be remaining in the tank following chemical cleaning, approximately 12 - 38\% $\left(6.8 \times 10^{3}-\right.$ $2.1 \times 10^{4}$ moles) was dissolved by the nitric acid leach. The amount of oxalic acid remaining in the solids and dissolved by the nitric acid leach was $2-5 \%$ of the oxalate added to the tank. 
This mass balance shows approximately half (54\%) of the oxalate added to Tank 5F was dissolved and removed with the liquid. Approximately $2-5 \%$ of the added oxalate formed precipitates with species such as nickel, manganese, and iron (II) and dissolved after nitric acid leaching. These streams leave about $40 \%$ of the added oxalate unaccounted for. As much as $30 \%$ of the oxalate may have decomposed to form carbon dioxide, which would leave about $10 \%$ of the added oxalate unaccounted for.

\subsection{CONCLUSIONS}

The conclusions from this work follow.

- Approximately 50\% of the oxalate added as oxalic acid was removed with the decanted liquid.

- Approximately 2-6\% of the oxalate (added to the tank as oxalic acid) formed precipitates with compounds such as nickel, manganese, sodium, and iron (II), and was dissolved with nitric acid.

- As much as $30 \%$ of the oxalate may have decomposed forming carbon dioxide.

\subsection{REFERENCES}

${ }^{i}$ G. D. Thaxton and W. J. Vetsch, “Tank 5 First Acid Strike Chemical Cleaning Report”, LWO-LWE-2008-00227, August 12, 2006.

${ }^{i i}$ M. S. Hay, K. P. Crapse, S. D. Fink, and J. M. Pareizs, "Characterization and Actual Waste Tests with Tank 5F Samples," WSRC-STI-2007-00192, Washington Savannah River Company (2007).

iii D. T. Herman, B. J. Wiersma, F. F. Fondeur, J. C. Wittkop, J. M. Pareizs, K. P. Crapse, M. S. Hay, M. R. Poirier and S. D. Fink, "Investigating Hydrogen Generation and Corrosion in the Treatment Tank and Potential Formation of a Floating Layer in Neutralizing Tank during Waste Tank Heel Chemical Cleaning,” WSRC-STI-2007-00209, April 30, 2007.

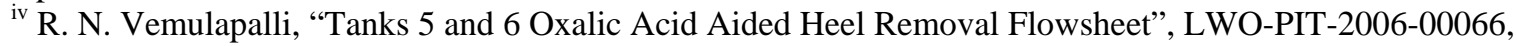
December 10, 2007.

${ }^{v}$ Donnie Thaxton, “Analyses for Dip Samples during Chemical Cleaning for Tanks 5 and 6”, HLE-TTR-2008-49, June 26, 2008.

${ }^{v i}$ G. D. Thaxton, “Tanks 5 and 6 Chemical Cleaning Process Samples”, HLE-TTR-2009-102, March 23, 2009.

${ }^{v i i}$ M. R. Poirier, “Analysis of Samples from Chemical Cleaning in Tank 5F”, SRNL3100-2008-00020, Rev. 3, May 5, 2009.

viii G. D. Thaxton and W. J. Vetsch, “Tank 5 Second Acid Strike Chemical Cleaning Report”, LWO-LWE-200800283, October 20, 2008.

${ }^{\text {ix }}$ G. D. Thaxton and W. J. Vetsch, "Tank 5 Acid and Deionized Water Spray Wash and Final Water Wash Report”, LWO-LWE-2008-00390, June 4, 2009.

${ }^{x}$ W. D. King and M. S. Hay, “Alternative Enhanced Chemical Cleaning: Basic Studies Results FY09”, SRNL-STI2009-00791, February 2010.

${ }^{x i}$ M. E. Garcia-Clavel, M. J. Martinez-Lope, and M. T. Casais-Alvarez, "Thermal Study of $\mathrm{NiC}_{2} \mathrm{O}_{4} * \mathrm{H}_{2} \mathrm{O}$ Obtained by a Solid State Reaction at Room Temperature and Normal Pressure”, Thermochimica Acta, vol. 118, pp. 123-134, 1987.

${ }_{\text {xii }}$ M. R. Poirier, F. F. Fondeur, D. M. Missimer, M. E. Summer, and S. D. Fink, “Analysis of Solids Remaining Following Chemical Cleaning in Tank 5F”, SRNL-STI-2010-00199, Match 29, 2010. 